resolving apparent contradictions. For the modern French pre-alpine landscape, there are several significant lessons:

- Forest cover defines the boundary conditions for flood magnitude and slope instability over multi-decadal to centennial timescales, which has been mainly anthropogenically controlled for at least two millennia. In system dynamic terms, land cover represents the set of "slow" processes that control the system's resilience (Dearing, 2008).

- In contrast, the key drivers of short-term flooding and slope instability at commune and sub-catchment levels are linked to specific meteorological events (snowmelt and summer storms) rather than local land-use change, except where there is exceptional land degradation.

- If $21^{\text {st }}$ century winter precipitation increases by $10-20 \%$, the predicted increase in the frequency and magnitude of large flood events in winter and spring could be amplified further as water storage, in the form of snow, is reduced.

- Reducing forest cover and/or increasing frequency/magnitude of flood events render the fluvial system rich in sediment. This not only increases the rate of lateral channel migration, a hazard for farmland and buildings, but also shifts the rivers (mainly through bank erosion) to a more sediment-rich state.

- Anticipating the effects of climate change thus needs to focus on mitigation and adaptation strategies for the likelihood of more frequent extreme meteorological events causing local flooding. However, careful management of land cover across the region will also be needed to raise general levels of flood protection in the winter and spring, and reduce the risk of drought and forest fire in the summer.
Data

Some of the data discussed here can be found at http://www.liv.ac.uk/geography/research_ projects/Levan/index.htm

\section{References}

Coulthard, T.J. and MacKlin, M.G., 2001: How sensitive are river systems to climate and land-use changes? A model-based evaluation, Journal of Quaternary Science, 16: 347-351.

Crook, D.S., Siddle, D.J., Jones, R.T., Dearing, J.A., Foster, G.C. and Thompson, R., 2002: Forestry and flooding in the Annecy Petit Lac Basin, 1730-2000, Environment and History, 8(4): 403-428.

Crook, D.S., Siddle, D.J., Dearing, J.A. and Thompson, R., 2004: Human Impact on the Environment in the Annecy Petit Lac catchment Haute-Savoie: A documentary approach, Environment and History, 10(3): 247-284.

Foster, G., e, et al, 2003: Meteorological and land use controls on geomorphic and fluvial processes in the pre-Alpine environment: an integrated lake-catchment study at the Petit Lac d'Annecy, Hydrological Processes, 17(16): 3287-3305.

Welsh, K.E., Dearing, J.A., Chiverrell, R.C. and Coulthard, T.J., 2009: Testing a cellular modelling approach to simulating late-Holocene sediment and water transfer from catchment to lake in the French Alps since 1826, The Holocene, 19: 785-798.

For full references please consult:

http://www.pages-igbp.org/products/newsletters/ref2011_2.pdf

\title{
Past land use and soil erosion processes in central Europe
}

\author{
Markus Dotterweich ${ }^{1}$ and Stefan Dreibrodt ${ }^{2}$ \\ ${ }^{1}$ Institute of Geography, University of Mainz, Germany; mail@markus-dotterweich.de \\ ${ }^{2}$ Institute for Ecosystem Research, University of Kiel, Germany
}

\section{0 years of land use and soil erosion data provide an insight into modern links between human activities and the environment.}

\section{Agricultural development and geomorphology}

The development of natural and socioecologically adapted agroecosystems, which have the capacity to ease demand on food and resources and mitigate climate change, is a major challenge. Looking at past land-use systems and their socio-economic history increases our understanding of slow processes and low-frequency events. These underlying processes appear to be key in assessing whether modern land-use systems will lead to sustainability or collapse.

In central Europe, phases of agricultural expansion and regression occurred with land clearance and reforestation back to the onset of agriculture, around 7500 years ago. Under natural conditions (except for short phases of severe climate deterioration in the early Holocene), the sheltering cover of vegetation and soil development largely mitigated geomorphic processes, resulting in a stable dynamic equilibrium (Dotterweich, 2008). With the clearing of forests, the natural water and matter fluxes changed into anthropogenically driven systems with greatly accelerated processes and higher vulnerability to soil erosion. Repeated or extreme events forced by climate change may have af- fected the fertility of the land to an extent that it could no longer be cultivated. On a local- to regional scale, this may occur surprisingly rapidly, especially in strong single events. As the system develops, two outcomes may occur: a) Driving forces may progress slowly, causing gradual and predictable degradation, or b) Exceptional

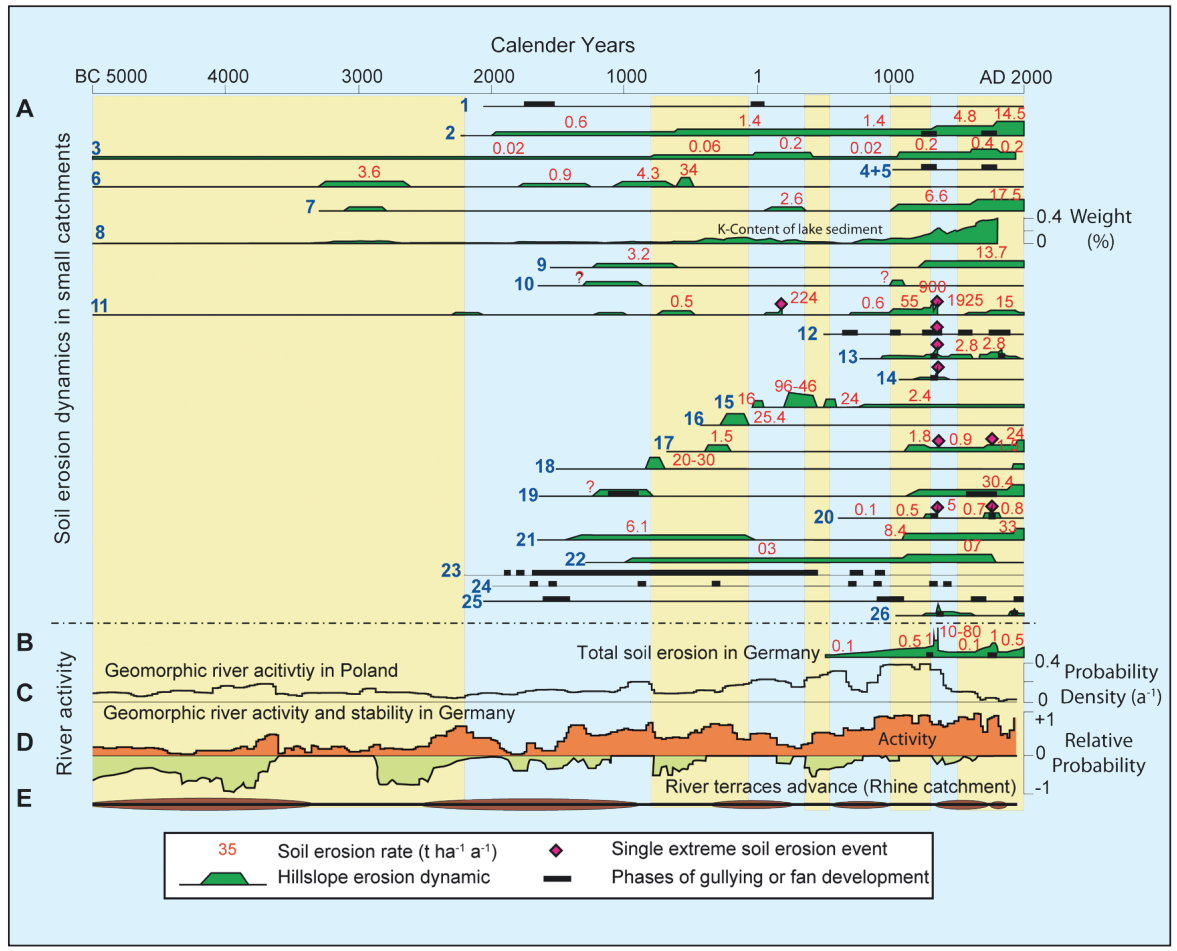

Figure 1: Dynamics of soil erosion in small catchments $(\boldsymbol{A})$ and river activity $(\boldsymbol{B}, \boldsymbol{C}, \boldsymbol{D}, \boldsymbol{E})$ in central Europe since the beginning of agriculture, based on studies by different authors. Blue numbers correlate to site names, type of geoarchive and references given in supplementary material (www.pages-igbp.org/products/newsletters/ref2011_2. pdf). Yellow shading represents cultural epochs (Figure modified from Dotterweich, 2008). 
events may trigger catastrophic changes, forcing premature abandonment of agricultural land. Regardless of the rate of degradation, the system will evolve through a reorganization phase and ultimately reach a new equilibrium, where either naturally or anthropogenically driven processes dominate the overall system.

As a result of these processes, erosion has changed soil conditions and patterns in many areas of Central Europe. Material has been washed downslope and gullies have incised, leading to the deposition of sediments at the slopes (colluvial layers), in floodplains (alluvial layers) or lakes (allochthonous input). These erosional landforms and depositional structures are geoarchives of past land use, human impact and climate change, at broad temporal (daily to millennia) and spatial (gully/slope to floodplains) scales. Efforts to retrieve these data have increased during the last few years (Fig. 1 and 2; Dotterweich, 2008; Dreibrodt et al., 2010; Notebaert and Ver-

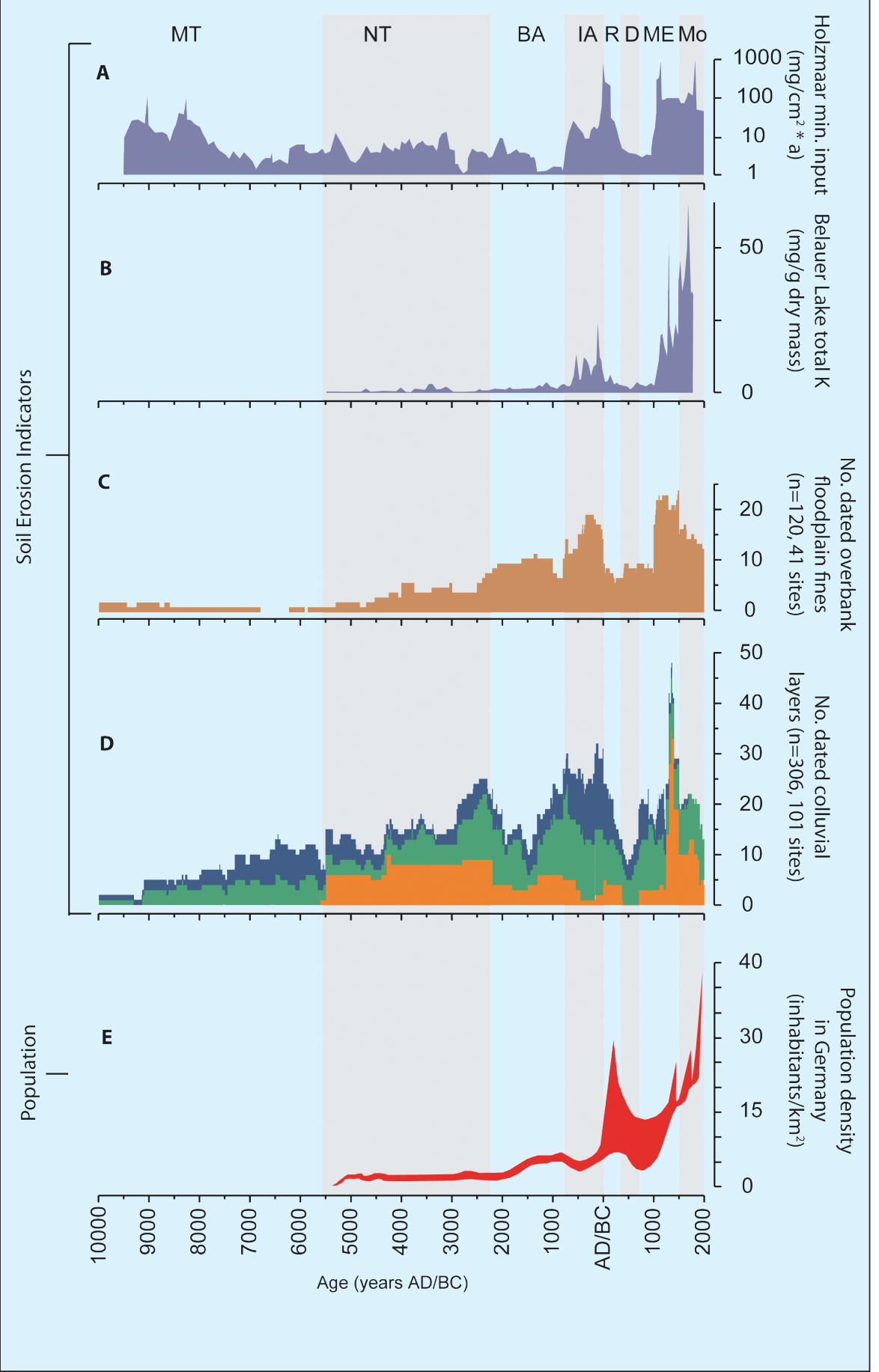

Figure 2: Records of historical soil erosion in Germany from two lake sediment sequences $(\boldsymbol{A}, \boldsymbol{B})$, alluvial sediments (C) and slope deposits (D), compared to population density (E; Dreibrodt et al., 2010). Three methods were used for dating of slope deposits: Archeological dating (embedded finds; orange), radiocarbon dating (green), and IRSL-dating (blue). Shaded areas reflect cultural periods: MT-Mesolithic Times, NT- Neolithic Times, BA-Bronze Age, IA-Pre-Roman Iron Age, R-Roman Imperial Times, D-DarkAges/Migration Period, ME-Medieval Times, MoModern Times. Note that the record of slope deposits and alluvial deposits for Modern Times underestimates soil erosion, as a lack of data exists for young deposits. straeten, 2010; Hoffmann et al., 2011). Based on many reconstructions of the history of soils, relief and river systems, we are now able to generalize about the fundamental effects of land use and climate on central European landscapes.

\section{Land use or climate?}

The observed variability in erosion reflects, to a large extent, the varying intensity of population pressure and agricultural land use in Germany. This is illustrated by the pronounced increase in soil erosion, particularly at the onset of and during the Neolithic times (ca. 5500-2200 BC in southern and central Germany) and by the distinctive decrease in soil erosion during the migration period (ca. 300-700 AD) and the early Medieval times (ca. 700-1000 AD) (Fig. 2) (Dotterweich, 2008). It seems that centennial-scale climate change affected the observed variability by modifying the boundary conditions for erosion. For example, there are few erosion records from the early and middle Bronze Age (ca. 2000$1600 \mathrm{BC}$ ), a period known to have been a prominent dry period in central Europe (Dotterweich, 2008). The most remarkable phase of soil erosion occurred in the first half of $14^{\text {th }}$ century, at the beginning of the Little Ice Age. The second well-known intense soil erosion phase occurred in the mid- $18^{\text {th }}$ to early $19^{\text {th }}$ century-at the end of the Little Ice Age. Historical records document extreme precipitation events during these two phases, implying an influence of climatic extremes on geomorphological processes. However, certain phases of the record remain unexplained. For instance, during Roman Emperor times (27 BC-476 AD) there is little indication of soil erosion even though there is no evidence for particularly dry conditions and population density was high (Fig. 2). As a general finding, the majority of the studies on soil erosion in small catchments indicate that sediment fluxes are highly sensitive to changes in local land use, while climate change plays a secondary role.

\section{Legacies of catastrophic events}

Most of the gully systems in central Europe today are a result of catastrophic rainfall events. In the year 1342 AD, for example, extreme erosion events initiated many gully systems and hill slope erosion delivering over $50 \%$ of the total colluvial material that exists today in the investigated areas in central Europe (Dotterweich, 2008). A few extreme events were responsible for most of the currently deposited slope sediments, significantly modifying flood and erosion regimes of the landscape. This period in history marks the change from 
natural- to human-dominated systemsa legacy that has ramifications for today's landscape. The ability of extreme events to cause steep changes in these landscapes, effectively changing the regional boundary conditions, should be seen as a warning for the potential impacts of extreme events in future climates. It also means that conventional modeling and assessment tools used for sustainable management strategies may be inadequate to accommodate legacies and complex interactions over decadal and centennial timescales because they generally don't integrate extreme events.

\section{Human-environment feedback}

In contrast to reconstructions of geomorphic and pedologic history, there are only a few studies concerning possible feedbacks from land use. These studies equate societal collapse to vulnerability to climate change, agricultural maladaptation or a mixture of both. For example, historical studies show that during the first half of the $14^{\text {th }}$ century, many villages in Germany were abandoned as an ultimate consequence of a combination of socio-cultural processes, crop failures and soil degradation (Bork et al., 1998; Dotterweich, 2008). Food prices became very expensive in several consecutive years of the first half of the $14^{\text {th }}$ century because of shortages as a consequence of soil degradation and economic mismanagement (Fraser, 2010). This unfavorable socio-economic, nutritional, and health situation might have prepared the ground for the Europeanwide pandemic, namely the Black Death, between 1347 and $1351 \mathrm{AD}$. In the $18^{\text {th }}$ to early $19^{\text {th }}$ centuries, soil erosion and crop failures led to major migration overseas. Soil erosion appears to have been one factor in a complex causality spiral leading to socio-economic instability and land-use changes.

\section{Modern day environments}

In light of historical and recent data (severe floods with high costs to our societies), we now have new insight into the interactions between societies and their environment. This type of research has the potential to help in the development of modern sustainable land-use strategies by providing evidence for the different timescales and complexity of interactions between human activities and geomorphic responses. However, many past studies combine and correlate different time series, assuming causality and neglecting the legacy of past forcings and responses. Future approaches must better distinguish proximate from ultimate causes to deliver a new understanding of complex system behavior. The research also has to extend the scope of analysis to the full spectrum of human-environment interactions including the demise of agriculturally marginal systems and the histories of more subtle, adaptive and cumulative changes and processes. This will extend our observation of background processes in modern human-dominated landscapes and their natural variability. Past records have an important role to play in the creation of adaption strategies for complex agricultural systems around the world.

\section{References}

Dotterweich, M., 2008: The history of soil erosion and fluvial deposits in small catchments of central Europe: Deciphering the long-term interaction between humans and the environment - A review, Geomorphology, 101(1-2): 192-208.

Dreibrodt, S., Lubos, C., Terhorst, B., Damm, B. and Bork, H.-R., 2010 Historical soil erosion by water in Germany: Scales and archives, chronology, research perspectives, Quaternary International, 222(1-2): 80-95.

Fraser, E.D.G., 2010: Can economic, land use and climatic stresses lead to famine, disease, warfare and death? Using Europe's calamitous $14^{\text {th }}$ century as a parable for the modern age, Ecological Economics, 70(7): 1269-1279.

Hoffmann, T., Thorndycraft, V.R., Brown, A.G., Coulthard, T.J., Damnati, B., Kale, V.S., Middelkoop, H., Notebaert, B. and Walling, D.E., 2011: Human impact on fluvial regimes and sediment flux during the Holocene: Review and future research agenda, Global and Planetary Change, 72: 87-98.

Notebaert, B. and Verstraeten, G., 2010: Sensitivity of West and Central European river systems to environmental changes during the Holocene: A review, Earth Science Reviews, 103(3-4): 163-182.

For full references please consult:

http://www.pages-igbp.org/products/newsletters/ref2011_2.pdf

\title{
Long-term perspectives on an iconic landscape: Origins and future trajectories of the "Ancient and Ornamental Woodlland", New Forest, UK
}

\author{
Mary Edwards ${ }^{1}$ and Michael J. Grant ${ }^{2,3}$ \\ ${ }^{1}$ Geography and Environment, University of Southampton, UK; M.E.Edwards@soton.ac.uk \\ Wessex Archaeology, Salisbury, UK; m.grant@wessexarch.co.uk; ${ }^{3}$ School of Geography, Geology and the Environment, Kingston University, UK
}

Paleoecology, in combination with more recent ecological observations and future climate projections, can play a key role in providing a robust basis upon which to build ecological management strategies for important biodiversity areas.

\section{The New Forest: Management dilemmas}

National parks in Britain are managed for multiple uses: they are often scenic areas and attract numerous visitors, they support local economies beyond tourism, particularly agriculture and forestry, and they are foci of biodiversity. Climate change introduces uncertainty to this challenging and sometimes conflicting land use mixture, and will affect management strategies for the $21^{\text {st }}$ Century. The New Forest (Fig. 1a), which lies just to the west of Southampton in central southern England, is one of the
UK's newest parks, and was established in 2005. Its landscapes and ecosystems give rise to outstanding lowland scenery and there are well-established amenity uses (it is only two hours from London). High levels of biodiversity, compared with the agricultural regions and urban areas that surround it, have attracted numerous national and European directives on species and habitat conservation. The medieval wood-pasture system maintained via customary rights and administered by a local court, is recognized as a unique cultural attribute that is closely linked with the For- est's ecology and landscapes. The future of the New Forest will depend upon the management strategies of government agencies, landowners, and the local user groups who practice customary rights such as stock grazing. Increasingly, it will depend upon the interaction of climatic factors and the constituent species of its ecosystems. The Forest features a range of highly valued habitats; here we examine one habitat type of high biodiversity and amenity value, the so-called "Ancient and Ornamental Woodland" (A\&O Woodland; Peterken et al., 1999; Tubbs, 2001; Fig. 1A). 